\title{
Primary Squamous Cell Carcinoma of the Liver: An Uncommon Finding in Contrast-Enhanced Ultrasonography Imaging
}

\author{
Yuji limuro Yasukane Asano $^{a} \quad$ Kazuhiro Suzumura ${ }^{a}$ \\ Akito Yada ${ }^{a}$ Tadamichi Hirano ${ }^{a}$ Hiroko lijima $^{b}$ \\ Shuhei Nishiguchi $^{\mathrm{b}}$ Seiichi Hirotac Jiro Fujimoto ${ }^{\mathrm{a}}$ \\ Departments of aSurgery, ${ }^{b}$ Medicine and 'Surgical Pathology, Hyogo College of \\ Medicine, Nishinomiya, Japan
}

\section{Key Words}

Squamous cell carcinoma · Liver · Liver cyst

\begin{abstract}
Primary squamous cell carcinoma (SCC) of the liver is rare tumor with an unfavorable prognosis. We report a case of advanced primary SCC of the liver arising adjacent to a nonparasitic liver cyst, invading into the right diaphragm and the right lung tissue. Contrast-enhanced ultrasonography (CE-US) demonstrated unique enhancement in the late vascular phase, which was incompatible with those observed in hepatocellular carcinoma, cholangiocellular carcinoma, or metastatic adenocarcinoma. The patient underwent surgical resection of the tumor followed by systemic chemotherapy with 5-fluorouracil (5-FU) and cisplatin (CDDP), while radiation chemotherapy was not applied because of relatively poor performance status. Although postoperative image analysis revealed no recurrence 4 months later, the patient died 13 months after the operation from recurrence. Immunohistological analysis of the resected specimen revealed that this SCC contained many capillary endothelial vessels expressing CD31 or CD34, possibly reflecting the unique imaging pattern in the late vascular phase of CE-US, which has been reported in choangiolocellular carcinoma. In addition, we reviewed which kind of treatment would be suitable for advanced hepatic primary SCC in the literature. From the review, it could be proposed that a combination of radiation therapy, systemic chemotherapy (5-FU and CDDP) and surgical resection, if possible, is appropriate for advanced primary SCC of the liver.
\end{abstract}




\section{Introduction}

Primary squamous cell carcinoma (SCC) of the liver is a rare tumor which has been sporadically reported. To our knowledge, only 24 cases have been reported in the English language literature. Of those cases, many developed in livers accompanied by nonparasitic hepatic cysts [1-5]. Solitary and multiple nonparasitic cysts originate from von Meyenburg's complexes and are lined with simple cuboidal or columnar epithelium. Primary SCC of the liver is generally considered to result from secondary squamous metaplasia of such biliary epithelium due to chronic inflammation and subsequent neoplastic transformation [3]. The prognosis of this tumor is very poor, and only a few cases survived more than 12 months even after treatment [6, 7]. In addition to surgical resection, radiation and chemotherapy have been tried to improve survival $[8,9]$. We report here an advanced case of primary SCC of the liver who received surgical resection and subsequent chemotherapy with low-dose 5-fluorouracil (5-FU) and cisplatin (CDDP). In addition, we reviewed in the literature which kind of treatment is appropriate if hepatic tumors are diagnosed as primary SCC.

Contrast-enhanced ultrasonography (CE-US) is a useful method for diagnosis of hepatic tumors. While findings of CE-US in hepatocellular carcinoma, cholangiocellular carcinoma, or metastatic adenocarcinoma of the liver have been well documented, there is no report of CE-US findings in primary hepatic SCC so far. CE-US findings of primary SCC of the liver were also reported here for the first time.

\section{Case Report}

A 73-year-old Japanese woman with a liver tumor and right hypochondrial pain was referred to our department in September 2006 for the purpose of surgical treatment, while her chief complaint started in June 2006. She visited a former hospital, and a liver tumor was suspected in the right lobe. Routine laboratory tests were within normal range. Enhanced computed tomography (CT) demonstrated an irregular low-density area with marginal enhancement adjacent to a nonparasitic liver cyst (fig. 1), while another nonparasitic cyst was also detected in segment 6 . Comparison between enhanced CT images in June 2006 (fig. 1a) and those in September 2006 (fig. 1b) revealed that invasion of this liver tumor into right diaphragm and lung tissue became obvious during this period. Magnetic resonance imaging (MRI) demonstrated an irregular liver tumor with low signal intensity in the T1-weighed images and slightly high signal intensity in the T2-weighed images (data not shown). Diffusion-weighted image showed abnormal intensity in the tumor adjacent to the nonparasitic cyst. Ultrasonography (US) revealed an irregular hyperechoic lesion in segments 7 and 8 in the liver (fig. 1c). CE-US using Levovist ${ }^{\circledR}$ (Berlex, Canada) showed blood flow into the tumor from the marginal area during the early vascular phase (fig. 1c; $23 \mathrm{~s}$ after injection). The increased tumor blood flow lasted during the late vascular phase except for the central area (fig. 1c; $60 \mathrm{~s}$ ); then, delayed parenchymal phase of the US showed an irregular hypoechoic area (fig. 1c; $5 \mathrm{~min}$ ). Meanwhile, whole body CT and gastrointestinal endoscopy demonstrated no other extrahepatic tumors. From these image analyses, intrahepatic cholangiocarcinoma or cyst adenocarcinoma in the liver was preoperatively suspected, even though the CE-US finding of the tumor in the late vascular phase was atypical. Needle biopsy was not performed to prevent iatrogenic dissemination.

In October 2006, she underwent hepatic resection of segments 7 and 8 including the nonparasitic cyst, in combination with partial resection of right diaphragm and right lung tissues. The tumor was irregular and white-colored, and its size was $10.0 \times 8.0 \mathrm{~cm}(\underline{\text { fig. }})$. The tumor macroscopically seemed to form a part of the nonparasitic cyst wall, invading to the liver, diaphragm and lung tissues. Histological examination revealed that the tumor consisted of moderately or partially well differentiated squamous carcinoma cells with keratinization, but not of any adenocarcinoma component (fig. $3 a-c)$. Invasion of the tumor cells into the lung tissue was also microscopically detected (fig. 3a, asterisk). Immunohistochemical analysis revealed that this tumor contained many capillary endothelial vessels 
which were positive for anti-CD31 (fig. 3d) or anti-CD34 (fig. 3e) antibodies, and that these vessels predominantly existed in the peripheral regions of the tumor. Meanwhile, the tumor was negative for immunostaining against thyroid transcription factor-1 (TTF-1), a pulmonary cell-selective transcription protein (data not shown).

After the operation, the patient underwent systemic chemotherapy with low-dose 5-FU (250 mg/ $\mathrm{kg}$ body weight/day) and CDDP ( $5 \mathrm{mg} / \mathrm{kg}$ body weight/day). These drugs were administered for 5 consecutive days with 2-day intervals for 4 weeks. Meanwhile radiation therapy could not be performed because of postoperative bleeding peptic ulcer. Four months after the operation, enhanced CT images revealed no recurrence in the remnant liver and surrounding tissues. However, recurrence appeared 11 months later, and she died 13 months after the operation.

\section{Discussion}

Primary SCC of the liver is a very rare tumor, and many of them exist adjacent to nonparasitic liver cysts, with a few exceptions $[7,10]$. While the precise mechanism why SCC develops in the liver is unclear, it is proposed that squamous epithelium lining liver cysts may undergo dysplasia, metaplasia and, ultimately, malignant transformation over the years [3]. In the present case, the SCC indeed existed adjacent to a nonparasitic cyst, forming a part of the cyst wall, suggesting that the tumor originated from the cyst wall. Strictly, it is difficult to distinguish primary SCC of the liver from hepatic invasion of pulmonary SCC in the present case, though the tumor was negative for anti-TTF-1 immunostaining. However, sequential preoperative image analysis strongly suggested that primary SCC of the liver invaded into the right diaphragm and lung tissue in this case.

In the diagnosis of primary hepatic SCC, preoperative findings of this tumor in CE-US have not been well defined in the literature. In the present case, the tumor was still hyperechoic with Levovist even in the late vascular phase. This observation was incompatible with typical CE-US findings of cholangiocarcinoma, metastatic adenocarcinoma, or hepatocellular carcinoma [11]. Meanwhile, CT and MRI images of the present tumor were almost compatible with those in previous hepatic SCC cases $[7,10,12]$. Immunohistochemical analysis (anti-CD31 or anti-CD34) revealed abundance of capillary endothelial vessels in this tumor. This observation may explain why the tumor showed hyperechoic findings even in the late vascular phase during CE-US, as reported in a case of cholangiolocellular carcinoma [13]. Collecting CE-US data concerning SCC will be required to define whether the present observation is specific to SCC or not. Preoperative needle biopsy might be recommended if a rare pattern of CE-US is preoperatively detected like in the present case, because the therapeutic strategy will be possibly changed due to the pathological diagnosis.

As for the treatment of primary SCC of the liver, surgical resection per se can lead to a good prognosis if the tumor stays within early stages, namely if the tumor invades only the subepithelial connective tissue of the cyst wall, but not the surrounding liver parenchyma $[14,15]$. However, primary SCC is often diagnosed after it has become advanced. In such cases, the tumor invades beyond the cyst wall and the liver parenchyma, leading to very poor prognosis. Before 1994, no case with survival $>6$ months was reported in such advanced patients [15]. Thereafter, radiation therapy or chemotherapy was tried to improve the prognosis, and relatively good survival was reported in a few cases [6-9]. We summarized which kind of therapy was applied to the patients with primary SCC of the liver when relatively good survival (>12 months) was reported in the English language literature (table 1). From the summary, it is 
suggested that surgical resection alone cannot promise good prognosis once the tumor has become advanced, and that radiation therapy or chemotherapy with 5-FU and/or CDDP should be recommended in combination with surgical resection. In the present case, the diagnosis of hepatic SCC was confirmed only after liver resection, and postoperative systemic chemotherapy with $5-\mathrm{FU}(250 \mathrm{mg} / \mathrm{kg}$ body weight/day) and CDDP ( $5 \mathrm{mg} / \mathrm{kg}$ body weight/day) was performed for 4 weeks (administration for 5 consecutive days with 2-day intervals). However, she did not undergo radiation therapy because of postoperative bleeding peptic ulcer. She died 13 months after the operation because of recurrence. These observations strongly suggest that radiation therapy in combination with chemotherapy and surgery should be applied if the hepatic tumor appears to be advanced primary SCC.

In summary, although primary SCC of the liver is very rare, if atypical hepatic tumor exists adjacent to a nonparasitic liver cyst, SCC also should be taken into the differential diagnosis. At present, there are no guidelines for adjuvant and palliative chemotherapy for primary SCC of the liver. However, it can be proposed that combination of radiation therapy, systemic chemotherapy, and surgical resection, if possible, should be applied if hepatic tumors are preoperatively confirmed as primary SCC.

\section{Disclosure Statement}

Yuji Iimuro and the co-authors have no conflict of interest. 


\begin{tabular}{r|l|l|l}
$\begin{aligned} \text { Case Reports in } \\
\text { Gastroenterology }\end{aligned}$ & $\begin{array}{l}\text { Case Rep Gastroenterol 2011;5:628-635 } \\
\text { DOl: 10.1159/000334425 }\end{array}$ & $\begin{array}{l}\text { Published online: } \\
\text { November 5, 2011 }\end{array}$ & $\begin{array}{l}\text { O 2011 S. Karger AG, Basel } \\
\text { ISSN 1662-0631 } \\
\text { www.karger.com/crg }\end{array}$ \\
\hline
\end{tabular}

Table 1. Primary SCC of the liver: literature review of treatment in patients with relatively good survival (>12 months)

\begin{tabular}{lllll}
\hline Reference & Age, sex & Clinical stage & Therapy & Survival \\
\hline Banbury et al., 1994 [14] & 59, female & not advanced & surgery only & $>16$ months \\
Weimann et al., 1996 [15] & 74, female & not advanced & surgery only & $>4$ years \\
Kaji et al., 2003 [12] & 67, female & advanced & hepatic arterial infusion of CDDP and 5-FU & 23 months \\
Hsieh et al., 2005 [8] & 65, male & advanced & surgery + systemic 5-FU + radiation & 18 months \\
Boscolo et al., 2005 [9] & 64, male & advanced & systemic CDDP and 5-FU + surgery & complete remission \\
Abbas et al., 2008 [6] & 28, female & advanced & surgery + radiation & $>18$ months \\
Naik et al., 2009 [7] & 56, male & advanced & radiation + surgery & $>6$ years \\
\hline
\end{tabular}

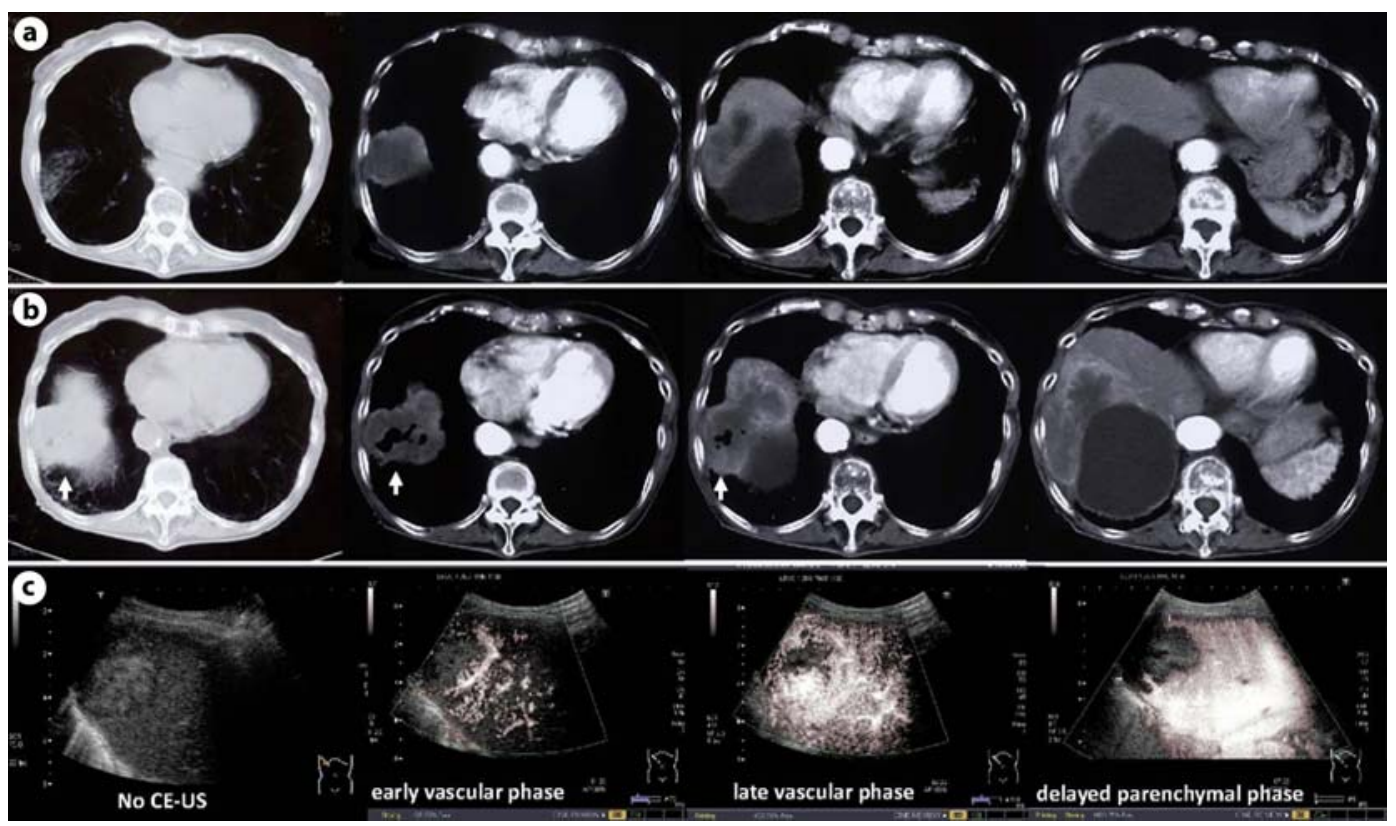

Fig. 1. Plain chest or enhanced abdominal CT on June 2006 (a) and September 2006 (b) of the hepatic tumor are shown. Comparison between these two series of CT images revealed that an irregular low-density hepatic tumor with marginal enhancement located adjacent to a nonparasitic liver cyst gradually grew and invaded into the diaphragm and the lung tissue. Arrows: lung tissues involved in the tumor. Abdominal US revealed an irregular hyperechoic lesion in segments 7 and 8 of the liver (c). CE-US demonstrated blood flow into the tumor from the periphery in the early vascular phase ( $23 \mathrm{~s}$ after the injection of Levovist). The contrast enhancement lasted until the late vascular phase (60 s) except for the central area (necrotic lesion). The delayed parenchymal phase of the US (5 min) showed an irregular hypoechoic area. 

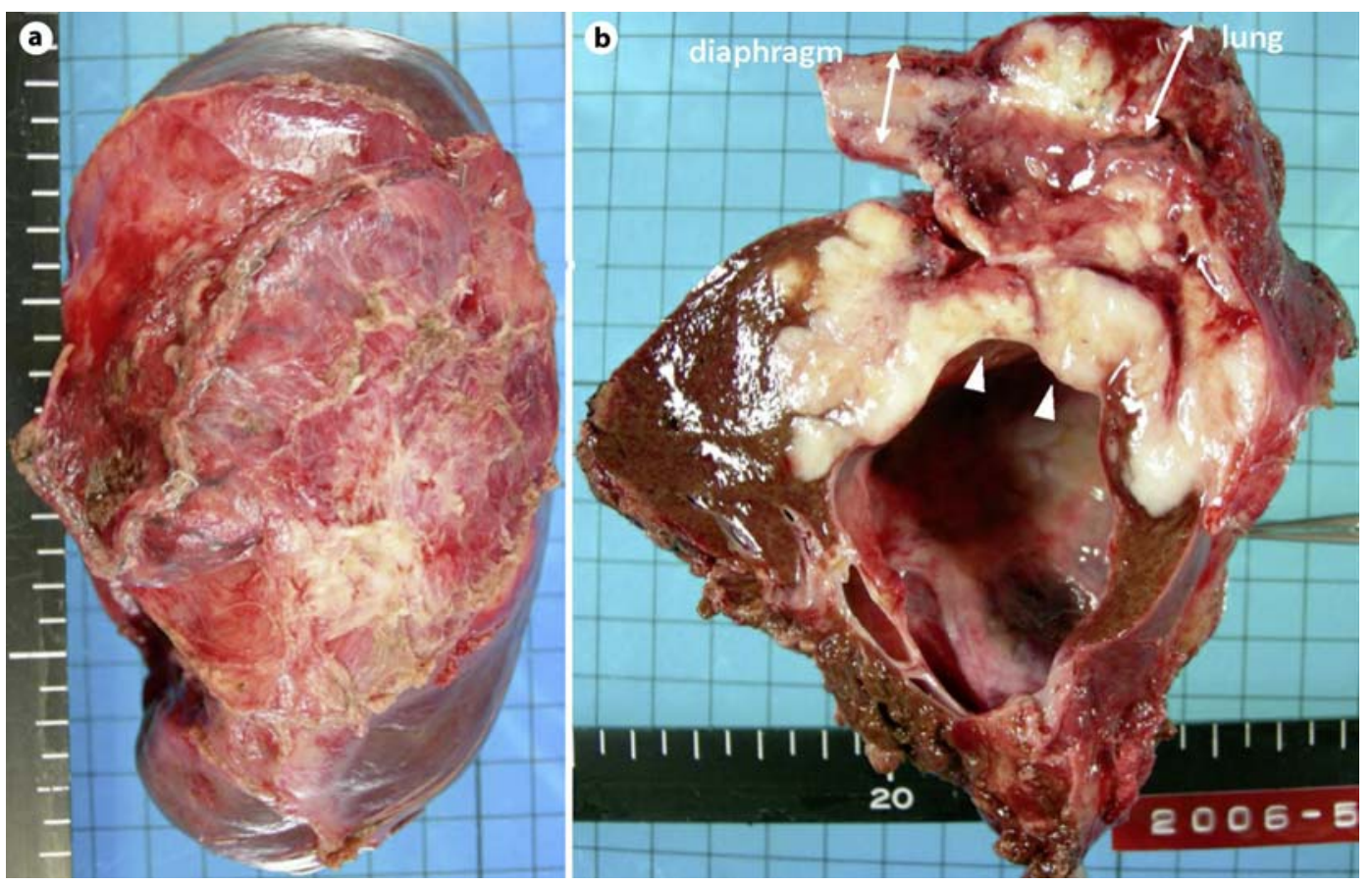

Fig. 2. Macroscopic findings of the resected tumor including diaphragm and lung tissue are shown (a). Coronal section of the specimen revealed that the tumor was irregular and white-colored, forming a part of the nonparasitic cyst wall, invading to the liver, diaphragm and lung tissue (b). 


\begin{tabular}{|c|c|c|c|}
\hline $\begin{array}{r}\text { Case Reports in } \\
\text { Gastroenterology }\end{array}$ & $\begin{array}{l}\text { Case Rep Gastroenterol 2011;5:628-635 } \\
\text { DOI: } 10.1159 / 000334425\end{array}$ & $\begin{array}{l}\text { Published online: } \\
\text { November 5, } 2011\end{array}$ & $\begin{array}{l}\text { (c) } 2011 \text { S. Karger AG, Basel } \\
\text { ISSN } 1662-0631 \\
\text { www.karger.com/crg }\end{array}$ \\
\hline
\end{tabular}

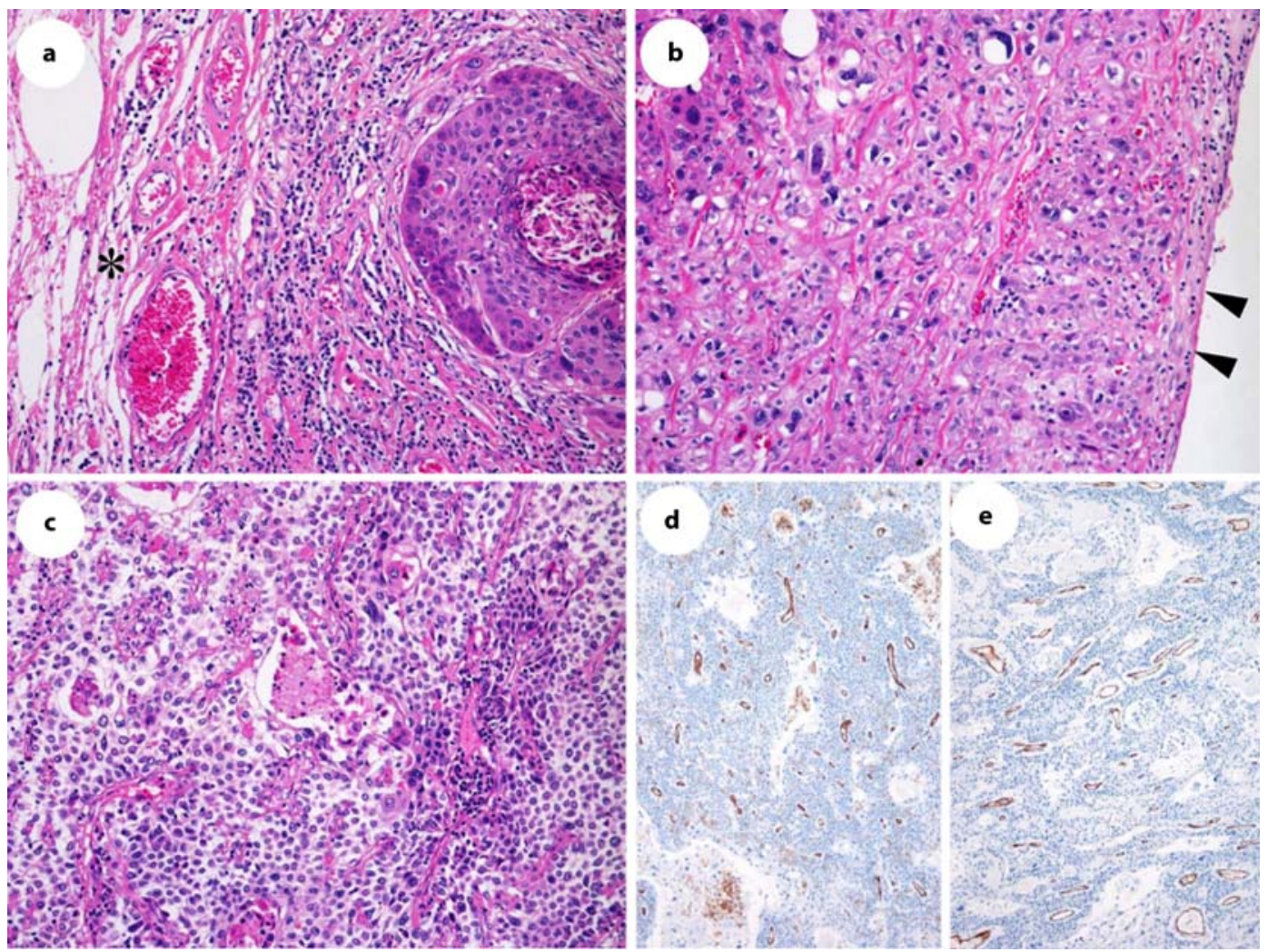

Fig. 3. Histological examination revealed that the tumor consisted of moderately $(\mathbf{b}, \mathbf{c})$ or partially well (a) differentiated squamous carcinoma cells with keratinization. Invasion of the tumor cells into the lung tissue was microscopically detected (a). Meanwhile, no adenocarcinoma component was detected in the specimen. Immunohistochemical analysis revealed that this tumor contained many capillary endothelial vessels which were positive for anti-CD31 (d) or anti-CD34 (e) antibodies. Asterisk: compressed lung tissue; arrowheads: wall of the nonparasitic cyst. H\&E staining: original magnification $\times 200$; immunostainings: original magnification $\times 100$.

\section{References}

1 Greenwood N, Orr WM: Primary squamous-cell carcinoma arising in a solitary non-parasitic cyst of the liver. J Pathol 1972;107:145-148.

2 Bloustein PA, Silverberg SG: Squamous cell carcinoma originating in a hepatic cyst. Case report with a review of the hepatic cyst-carcinoma association. Cancer 1976;38:2002-2005.

3 Gresham GA, Rue LW 3rd: Squamous cell carcinoma of the liver. Hum Pathol 1985;16:413-416.

4 Lynch MJ, McLeod MK, Weatherbee L, Gilsdorf JR, Guice KS, Eckhauser FE: Squamous cell cancer of the liver arising from a solitary benign nonparasitic hepatic cyst. Am J Gastroenterol 1988;83:426-431.

5 Pliskin A, Cualing H, Stenger RJ: Primary squamous cell carcinoma originating in congenital cysts of the liver. Report of a case and review of the literature. Arch Pathol Lab Med 1992;116:105-107.

6 Abbas R, Willis J, Kinsella T, Siegel C, Sanabria J: Primary squamous cell carcinoma of the main hepatic bile duct. Can J Surg 2008;51:E85-E86.

7 Naik S, Waris W, Carmosino L, Mehrishi A, Saif MW: Primary squamous cell carcinoma of the liver. J Gastrointest Liver Dis 2009;18:487-489.

$\checkmark 8$ Hsieh CB, Chen CJ, Yu JC, Chang TM, Gao HW, Liu YC: Primary squamous cell carcinoma of the liver arising from a complex liver cyst: report of a case. Surg Today 2005;35:328-331. 
9 Boscolo G, Jirillo A, Da Pian P: Complete remission of poorly differentiated squamous liver carcinoma after systemic chemotherapy and surgery. A case report. Tumori 2005;91:71-72.

10 Saito T, Harada K, Tsuneyama K, Hirano M, Amaya S, Sasaki M, Kaneko S, Kobayashi K, Nakanuma Y: Primary squamous cell carcinoma of the liver producing parathyroid hormone-related protein. J Gastroenterol 2002;37:138-142.

-11 Furuse J, Nagase M, Ishii H, Yoshino M: Contrast enhancement patterns of hepatic tumours during the vascular phase using coded harmonic imaging and Levovist to differentiate hepatocellular carcinoma from other focal lesions. Br J Radiol 2003;76:385-392.

-12 Kaji R, Sasaki N, Tateishi I, Nagata E, Okabe Y, Yoshida T, Sata M, Ueno T: A case report of primary hepatic squamous cell carcinoma that remarkably responded to low dose arterial injection of anti-cancer drugs. Kurume Med J 2003;50:71-75.

13 Joshita S, Ichijo T, Suzuki F, Yokoyama T, Sugiyama Y, Fukushima M, Kamijo A, Komatsu M, Umemura T, Yoshizawa K, Miyagawa S, Tanaka E: A case of well-differentiated cholangiolocellular carcinoma visualized with contrast-enhanced ultrasonography using Sonazoid. Hepatol Res 2009;39:207-212.

14 Banbury J, Conlon KC, Ghossein R, Brennan MF: Primary squamous cell carcinoma within a solitary nonparasitic hepatic cyst. J Surg Oncol 1994;57:210-212.

15 Weimann A, Klempnauer J, Gebel M, Maschek H, Bartels M, Ringe B, Pichlmayr R: Squamous cell carcinoma of the liver originating from a solitary non-parasitic cyst: case report and review of the literature. HPB Surg 1996;10:45-49. 